\title{
MUDANÇAS NAS POLÍTICAS CURRICULARES DO ENSINO MÉDIO NO BRASIL: REPERCUSSÕES DA BNCCEM NO CURRÍCULO MINEIRO
}

\author{
SAMILLA NAYARA DOS SANTOS PINTO \\ https://orcid.org/0000-0001-9208-2071 \\ SAVANA DINIZ GOMES MELO \\ https://orcid.org/0000-0003-0415-5344
}

\begin{abstract}
RESUMO: Este artigo, fundamentado em pesquisa bibliográfica e documental, teve como objetivo analisar o conjunto de políticas curriculares dirigidas ao ensino médio a nível nacional, no período de 1990 a 2018 e sua expressão na Rede Estadual de Ensino de Minas Gerais. Para tanto se buscou apreender as definições da Lei n. 13.415/2017, da Base Curricular desta etapa de ensino, e do Currículo Referência de Minas Gerais, aprovado no fim de 2020. A expectativa é apresentar elementos para a análise da concepção e sentido da reforma do ensino médio no país e no contexto mineiro. As considerações deste estudo sinalizam que as novas configurações dirigidas à última etapa da educação básica convergem para uma formação destituída de sentido crítico e voltada para a aplicabilidade de conteúdos orientados por uma lista de competências e habilidades. O discurso de flexibilização é retomado na definição dos itinerários formativos, enfatizando o empreendedorismo como elemento chave para atender os requerimentos econômicos; além disso, há forte tendência à privatização do ensino médio tanto por meio de parcerias com o setor privado para a oferta desses itinerários, quanto pela possibilidade de implementação de escolas públicas com gestão privada, como vem sendo anunciado pelo Governo de Minas Gerais.
\end{abstract}

Palavras-Chave: novo ensino médio, BNCC, currículo, Minas Gerais.

\section{CHANGES ON CURRICULUM POLICIES FOR HIGH SCHOOL IN BRAZIL: REPERCUSSION OF BNCCEM AT MINAS GERAIS STATE CURRICULUM}

\begin{abstract}
This paper, founded in literature and documentary review, sought to analyse the set of curriculum policies addressing high school at national level, in the period from 1990 to 2018 and its expression at Minas Gerais State Education System. For that, it seeks to appreh end the definitions of Law n. 13.415/2017, of Curricular Basis for that level of education, and of the document entitled "Minas Gerais Reference Curriculum", approved at the end of 2020. The expectation is to present elements for the analysis of the repercussion of the high school reform in Brazil specifically in the state of Minas Gerais. The evidence points out that the new configurations addressed to the laststage of fundamental

\footnotetext{
${ }^{1}$ Prefeitura de Belo Horizonte (PBH) e Universidade Federal de Minas Gerais (UFMG). Belo Horizonte, MG, Brasil. <samilla.nayara@edu.pbh.org.br>

${ }^{2}$ Universidade Federal de Minas Gerais (UFMG). Belo Horizonte, MG, Brasil.<sdgmufmg2@gmail.com>

Educação em Revista|Belo Horizonte|v.37|e34196|2021
} 
education converge to an education deprived of criticalsense and conducted by the application of contents by a list of competencies and skills. The relaxation discourseis resumed in the definition of educational trajectories, emphasizing self-management as a key elementto understand the economical requirements; also, there is a strongtendency for privatization of high school by partner ships with private sector for of feringthose trajectories, as well as the possibility to implement public schools withprivate management, as has been studied by Minas Gerais Government.

Keywords: new high school, BNCC, curriculum, Minas Gerais.

\section{CAMBIOS EN LAS POLÍTICAS CURRICULARES DE LA ENSEÑANZA MÉDIA EN BRASIL: REPERCUSIONES DE LA BNCCEM EN EL CURRÍCULO DE MINAS GERAIS}

RESUMEN: Eso estudio, fundado en pesquisa bibliográfica y documental, ha buscado analizar el conjunto de políticas curriculares dirigidas a la enseñanza media a nivel nacional, em el periodo de 1990 a 2018 y su expresión em la Red Estadual de Educación de Minas Gerais. Para tanto, busca aprehender las definiciones de la Ley n. 13.415/2017, de la Base Curricular de esa etapa de enseñanza, y del documento intitulado "Currículo Referencia de Minas Gerais", aprobado em el término de 2020. La expectativa es presentar elementos para el análisis de las repercusiones de la reforma de la enseñanza media en Brasil y em el Estado de Minas Gerais. Las conclusiones señalan que las nuevas configuraciones dirigidas a la última etapa de la educación básica convergen para una formación privada de sentido crítico y direccionada para la aplicación de contenidos por medio de una lista de competencias y habilidades. El discurso de flexibilización retomado en la definición de los itinerarios formativos, enfatizando el emprendimiento como elemento clave para atender las demandas financieras; también hay fuerte tendencia para la privatización de la enseñanza media por medio de parecerias com el sector privado para la oferta de esos itinerarios, como por la posibilidad de implementación de escuelas públicas com gestión privada, como viene siendo estudiado por el Gobierno de Minas Gerais.

Palabras-clave: nueva enseñanza media, BNCC, currículo, Minas Gerais.

\section{INTRODUÇÃO}

As novas formas adquiridas pelo capitalismo em nível mundial, nas últimas décadas, implicaram substanciais mudanças para a educação, sendo esta compreendida pelos setores empresariais como importante via para se atingir interesses econômicos. A partir dos anos de 1990 observa-se a influência de organismos internacionais tais como Banco Mundial, o Fundo Monetário Internacional (FMI) e o Banco Interamericano de Desenvolvimento (BID) na construção de um modelo hegemônico de educação, a fomentar os requerimentos exigidos pelo processo de globalização econômica. $\mathrm{Na}$ busca por maior produtividade, essas organizações pautaram os rumos dos sistemas educativos de países latinoamericanos, indicando um conjunto de reformas mediante discurso salvacionista de melhoria da qualidade da educação e das condições econômicas e sociais desses países.

No Brasil, as reformas educacionais da década de 1990 foram colocadas em curso no Governo de Fernando Henrique Cardoso, fundamentando-se em princípios como qualidade, competitividade, eficiência e eficácia - conceitos importados do modelo gerencial, em que se baseiam os setores privados. As transformações no âmbito da educação no país caminharam rumo ao estabelecimento de uma nova lógica que alterou aspectos relativos ao financiamento, à gestão, ao currículo, à avaliação, às condições gerais de trabalho nas instituições, entre outros.

Considerando a centralidade sobre o conjunto das políticas curriculares, convém esclarecer que, dentre as teorias de currículo existentes, este estudo se fundamenta nas teorias críticas ${ }^{3}$, as quais emergiram no século XX (SILVA, 2010). Elas permitem uma análise em profundidade haja vista que colocam em questão os pressupostos dos arranjos sociais e educacionais, além de questionar e criticar as

\footnotetext{
${ }^{3}$ Sobre teorias críticas de currículo ver: Apple (2005; 2006); Sacristán (2000); Moreira (1990; 1998) e Silva (2010). Educação em Revista|Belo Horizonte|v.37|e34196|2021
} 
formas dominantes de conhecimento e a maneira como o currículo é implementado nas instituições escolares. Os adeptos das teorias críticas, entre os quais se evidencia Michael Apple, consideram que o currículo se relaciona diretamente com o poder, que se expressa a partir da seleção de conhecimentos. Preocupam-se com os motivos pelos quais determinados conteúdos são privilegiados em detrimento de outros. Ao considerarem o contexto em que se inserem, a escola e o currículo se apresentam submetidos aos aspectos econômicos e sociais, correspondendo o segundo aos interesses dos grupos dominantes (SILVA, 2010). Tanto é que para Apple (2006), o currículo não é apenas uma simples colagem objetiva de informações, já que estas são sempre frutos de determinados agrupamentos sociais que decidem o que será transmitido nas salas de aula. Com esses entendimentos, as teorias críticas do currículo propõem uma formação de sujeitos conscientes das relações de dominação existentes nos contextos em que estão inseridos.

Embora a discussão sobre a teoria de currículo seja relevante, seu desenvolvimento extrapola o escopo deste estudo ${ }^{4}$ que possui seu cerne na concepção da política. Sua intenção é, como já referida, analisar de forma preliminar a essência e o sentido do conjunto das políticas curriculares direcionadas ao ensino médio em nível nacional, no período de 1990 a 2018, e sua expressão na Rede Estadual de Ensino de Minas Gerais.

Convém ainda destacar que, pelo presentismo do documento que institui o novo ensino médio em Minas Gerais, os resultados ainda são inconclusos e, portanto, de difícil apreensão no momento, sendo oportuno esse aspecto se conformar em objeto de estudos futuros.

Quanto à pesquisa bibliográfica, cabe esclarecer que esta foi realizada para as pesquisas anteriores já citadas ${ }^{5}$, e a partir delas se incidiu um recorte sobre as que contribuem para a leitura dos documentos em questão neste artigo. Dentre os estudos selecionados encontram-se Freitas (2015b), Peroni e Caetano (2015), Cury, Reis e Zanardi (2018) e Hypólito (2019) que contribuem para a análise da Base Nacional Comum Curricular (BNCC), sendo destacado o processo de sua formulação, os atores envolvidos - públicos e privados, os documentos legais que a antecederam e constituíram-se como importantes substratos para sua conformação, e ainda as suas relações com a economia. Com o objetivo de compreender as especificidades dessa política curricular para o ensino médio, os estudos de Motta e Frigotto $(2017)$ e Silva $(2015 ; 2018)$ apontam importantes análises acerca da nova organização dessa etapa de ensino iniciada pela aprovação da Lei n. 13.415/2017 e suas implicações para a formação das juventudes, sobretudo das classes populares. A leitura dos documentos anteriores à aprovação da referida Lei e da Base Nacional Comum Curricular do ensino médio (BNCCEM) aliada às análises desses estudos revelam a submissão do ensino médio aos interesses econômicos, com alta lucratividade para instituições privadas a partir, por exemplo, da venda de consultorias e materiais didáticos. Esses estudos serão abordados de maneira aprofundada ao longo do texto, possibilitando uma análise preliminar sobre as concepções que fundamentam o novo ensino médio no Estado de Minas Gerais colocado em curso mediante o documento intitulado Currículo Referência de Minas Gerais, de 2021.

Posto isso, pode-se considerar que um marco importante das reformas curriculares na educação brasileira encontra-se na aprovação da Lei de Diretrizes e Bases da Educação Nacional (LDBEN), em 1996, que representou a síntese das alterações pretendidas - incluindo, por exemplo, a criação de um Sistema Nacional de Avaliação para todas as etapas e níveis da educação, e a referência para a construção de um projeto nacional de currículo a ele articulado. Para o ensino médio, especificamente, a referida Lei situa-o como última etapa da educação básica, sendo sua oferta dever do Estado, e apresenta, entre as demais definições presentes em seu texto, as orientações para a estrutura curricular desta etapa de ensino.

As diretrizes e parâmetros curriculares aprovados em 1998 e 1999, respectivamente, trouxeram à tona a noção de competências atribuídas à formação, dando sequência a um processo de

\footnotetext{
${ }^{4}$ Este estudo é fruto de dissertação de mestrado concluída em 2018 (PINTO, 2018) e integra a Pesquisa intitulada: "Piso Salarial Profissional Nacional no Brasil: incidências sobre a remuneração, carreira e atuação sindical”, desenvolvida com apoio da Fundação de Amparo à Pesquisa do Estado de Minas Gerais (FAPEMIG), Edital No 02/2016 - Programa Pesquisador Mineiro - PPM $\mathrm{X}$.

${ }^{5}$ Refere-se às pesquisas citadas na Nota 1.

Educação em Revista|Belo Horizonte|v.37|e34196|2021
} 
articulação, mais nítido, entre educação e economia - voltada a atender os requerimentos das atividades produtivas. A partir de então, os delineamentos elaborados no tocante ao currículo do ensino médio foram muitos, transformando essa etapa de ensino em um alvo de constantes alterações. O conjunto de políticas curriculares a ela direcionadas expressa as intensas disputas na elaboração de um projeto de ensino médio mais atrativo aos interesses econômicos.

Atualmente, a reforma posta em curso através da aprovação da Lei n. 13.415/2017, corroborada pela BNCCEM, representa o acúmulo de projetos elaborados ao longo dos governos nacionais desde 1995. Ela retoma, de maneira intensificada, o que se pretendia com a definição das Diretrizes Curriculares Nacionais para o Ensino Médio (DCNEM), em 1998, direcionando a formação a uma lista de competências e habilidades, conferindo à educação o reducionismo a respostas imediatistas e destituídas de pensamento crítico. As definições presentes na Lei n. 13.415/2017 e na BNCCEM encontrarão eco nos Estados, uma vez que estes reorganizarão o currículo do ensino médio a partir de seus conteúdos. Em Minas Gerais, o denominado novo ensino médio é colocado em curso a partir do Currículo Referência, aprovado em 2021.

Com vistas ao aprofundamento do tema, o presente artigo empenha-se à análise do conjunto de políticas curriculares dirigidas ao ensino médio em âmbito nacional, considerando o período de aprovação das DCNEM (1998) à BNCCEM (2018). E, a partir do atual documento curricular de Minas Gerais dedica-se a uma primeira análise das repercussões da política curricular nacional sobre a reestruturação do novo ensino médio na Rede Estadual de Ensino de Minas Gerais (REE/MG).

Para tanto, o artigo divide-se em três seções. A primeira apresenta a análise das políticas curriculares instituídas em nível nacional, com destaque para os discursos oficiais e suas concepções sobre o ensino médio. A segunda dedica-se à apresentação do contexto de formulação da BNCCEM e suas definições a partir da aprovação da versão final. E, por último, são apresentados elementos considerados importantes a esse estudo, relativos ao texto do Currículo Referência de Minas Gerais, aprovado em abril de 2021.

\section{TRÊS MOMENTOS DAS POLÍTICAS CURRICULARES PARA O ENSINO MÉDIO NO BRASIL}

Ao analisar o conjunto de políticas curriculares elaborados para o ensino médio, em nível nacional, no recorte temporal entre 1990 e 2018, observam-se três diferentes momentos quanto ao discurso oficial: o primeiro refere-se ao discurso da flexibilização curricular, depois se fortalece o tema da inovação e, em terceiro a retomada da flexibilização, mas revestida da concepção de atratividade e protagonismo juvenil. Essas políticas se complementam em partes, ora suavizam o esvaziamento da formação, ora a intensificam. Esses momentos serão detalhados a seguir.

\section{$1^{\circ}$ momento: flexibilização curricular}

No bojo das reformas educacionais desencadeadas na década de 1990, se insere a definição das DCNEM/1998 e dos Parâmetros Curriculares Nacionais para o Ensino Médio (PCNEM), em 1999. Tais documentos legais colocaram em curso mudanças relativas ao currículo do ensino médio por meio da adoção de conceitos como: flexibilização, autonomia, descentralização, competências e habilidades.

A noção de competências surgiu nos países centrais e sua difusão, no contexto educacional, ocorreu através de projetos formulados por organismos internacionais, cujos interesses econômicos são evidenciados no relatório da Organização das Nações Unidas para a Educação, Ciência e Cultura (UNESCO) publicado em 1973, e em publicações dos Estados Unidos, em 1983. A adoção das competências nas políticas curriculares contribuiu para o estabelecimento de um novo arranjo cultural e uma nova relação entre trabalho e educação tanto para os estudantes, quanto para as empresas (SILVA, 2009).

Nessa direção, os estudantes passam a atentar-se para o suposto desenvolvimento de capacidades que os qualifiquem e possibilitem um trabalho futuro, e as empresas passam a requerer essas competências em suas formas de gestão, estabelecendo a subordinação da formação aos seus novos 
requerimentos (SILVA, 2009; MOEHLECKE, 2012). Considera-se que a adoção da noção de competências adicionada à concepção de um currículo mais flexível foram os eixos centrais da reforma do ensino médio nesse período.

As DCNEM/1998, aprovadas no governo de Fernando Henrique Cardoso foram duramente criticadas, sendo alvo de muitos debates por parte de membros da educação e de especialistas da área. O tema entrou na agenda pública novamente no início do Governo Lula. Em maio de 2003, a Secretaria de Educação Média e Tecnológica (SEMTEC), vinculada ao Ministério da Educação (MEC), realizou o Seminário Nacional intitulado Ensino Médio: construção política, onde estiveram presentes representantes do Governo Federal, das Secretarias Estaduais de Educação, pesquisadores e entidades científicas.

As discussões realizadas no âmbito desse Seminário culminaram na publicação do Documento à Sociedade, apresentado em 2004. Nesse Documento, elucidaram-se novas concepções para o ensino médio a partir da articulação entre os eixos conbecimento, trabalho e cultura, com vistas à definição de uma formação que propiciasse a construção de sujeitos autônomos, preparados para as atualizações do mundo do trabalho e protagonistas nas relações de cidadania.

Diante disso, colocou-se em pauta a redefinição curricular, com base nos conceitos trabalho, ciência e cultura, e voltada para o reconhecimento dos estudantes. Nesse bojo, o texto do PCNEM/1999 sofreu alterações resultando na publicação das Orientações Curriculares Nacionais para o Ensino Médio, em 2006. O novo texto apresentava maior abertura para as escolas discutirem seus currículos conforme suas organizações e demandas locais. Em contrapartida, novas proposições foram apresentadas pelas políticas curriculares definidas a posteriori, repercutindo o discurso da inovação curricular.

\section{$2^{\circ}$ momento: inovação curricular}

Em 2009, surgiu uma nova orientação para o currículo do ensino médio no Brasil, a partir do lançamento do Programa Ensino Médio Inovador (PROEMI). O objetivo desse Programa era apoiar e fortalecer propostas curriculares inovadoras em escolas estaduais de ensino não profissional. Entre as suas definições, faziam-se presentes a ampliação da carga horária de formação para 3.000 horas; a utilização de vinte por cento da carga horária total para atividades práticas e disciplinas eletivas, de escolha do estudante; e a organização curricular articulada ao Exame Nacional do Ensino Médio (ENEM).

Esse Programa inaugurou o discurso oficial da inovação curricular, por meio do qual evidenciaram-se estratégias baseadas na necessidade de tornar a formação mais atrativa aos jovens evitando, assim, as altas taxas de repetência e evasão escolar. A partir disso, apresentaram a proposta de um currículo articulado entre uma base única e outra diversificada, que atendesse os múltiplos interesses dos estudantes, e fundamentada na concepção de trabalho enquanto princípio educativo (MOEHLECKE, 2012). Embora o discurso oficial tenha se revestido de uma perspectiva progressista de ensino médio, no âmbito prático o PROEMI não prosperou como o previsto, se limitando a uma medida pouco efetiva no alcance de suas metas.

Ainda que o Programa não tenha se mantido, suas ideias foram consumidas no texto das DCNEM/2011, durante o Governo Dilma. Essas Diretrizes fundamentaram-se na inovação curricular mantendo, contudo, a noção de competências e habilidades. Ressalta-se a permanência do discurso da flexibilização curricular, mas sob a roupagem da diversidade, haja vista que o termo foi um dos eixos duramente criticados nas DCNEM/1998 (MOEHLECKE, 2012). A ênfase na diversidade constituiu o discurso, as políticas e os programas formulados durante os governos de Lula e Dilma.

Essas Diretrizes, todavia, não se mantiveram como tal por muito tempo, sendo alvo de novas reformulações em seu texto as quais, por conseguinte, originaram a implantação da Resolução do Conselho Nacional de Educação (CNE) e da Câmara de Educação Básica (CEB) - n. 2/2011. As DCNEM/2012 apresentaram, como principal alteração, a organização curricular mediante o estabelecimento de áreas do conhecimento. No mesmo ano, o deputado Reginaldo Lopes (Partido dos Trabalhadores/MG), iniciou a Comissão Especial para promoção de estudos e proposições para o ensino médio. Após dezenove meses de trabalho com foco sobre o tema se apresentou o Projeto de Lei n. 6.840/2013 (SILVA, 2015). Tal PL consistia em duas grandes propostas para o currículo da última etapa da educação básica. A primeira relacionava-se à criação de opções formativas na grade curricular, e a 
segunda à adoção de temas transversais. Apesar de esse Projeto não ter sido aprovado, boa parte de seu conteúdo foi reaproveitado na elaboração da MP n.746/2016 que, a posteriori, transformou-se em Lei n. 13.415/2017. Krawczyk (2014), ao analisar o contexto de mudanças nas políticas para o ensino médio no Brasil, sinalizou que as movimentações observadas na educação, em especial nessa etapa de ensino, revelaram acentuada aproximação entre projeto educacional e setor privado. Esse estreitamento, por sua vez, culminou na elaboração de um plano de ensino médio voltado à aplicabilidade do conhecimento em detrimento de uma formação crítica. O que se pode notar, nitidamente, no terceiro momento das políticas curriculares.

Diante dos delineamentos que culminaram na aprovação da atual reforma do ensino médio, adota-se a ideia de esvaziamento curricular.

\section{$3^{\circ}$ momento: esvaziamento curricular}

Em 2015, no bojo do segundo Governo Dilma, o documento Pátria Educadora: a qualificação do ensino básico como obra de construção nacional, é formulado pela Secretaria de Assuntos Estratégicos (SAE), com o objetivo de promover a reestruturação da educação, justificada pela necessidade de melhoria da qualidade do ensino público ofertado no país.

No que concerne ao currículo, o documento apontou a necessidade de uma mudança radical em sua forma de organização, principalmente na sua grade de conteúdos. Considerava-se que o modelo de currículo até então estruturado não era eficiente por se valer de um ensino pautado no "enciclopedismo raso e informativo". Nessa direção, afirmou a pertinência de uma educação fundamentada nas habilidades centrais de análise verbal e raciocínio lógico, enfatizando a importância dos conteúdos de Português e Matemática, em detrimento de demais conteúdos como Arte.

Promoveu-se com o Pátria Educadora um discurso oficial voltado para o estreitamento curricular, no qual é retirada a atenção sobre a parte da formação humana para se preconizar reforços sobre as habilidades requeridas pelos setores empresariais. Além disso, reduziu-se problemas de aprendizagem ao aspecto de "barreiras cognitivas", desconsiderando os contextos de produção desses problemas apresentados pelos estudantes, sobretudo oriundos das camadas sociais mais empobrecidas. Negligencia-se o papel do Estado na garantia das necessárias condições para acesso, permanência e conclusão dos estudos desses estudantes.

Freitas (2015a), em posição crítica ao Pátria Educadora, aponta que o discurso empresarial, base da construção desse documento, ressalta a necessidade de se inserir um novo formato de disciplinamento como forma de superação dessas barreiras cognitivas. Esse novo formato ocorreria através da reformulação curricular, indicando uma formação mais direcionada à aquisição de habilidades e competências práticas. Conforme o autor, essa ação poderia ser traduzida como "autorização aos mais pobres, depois de cumpridas as exigências escolares, cruzar a fronteira da inclusão em direção ao mercado de trabalho como produtores de bens e serviços, disciplinados, atentos, prestativos e com algum raciocínio lógico e capacidade de escrita", dando-lhes a permissão para se integrarem aos novos requerimentos apresentados pelo processo de trabalho empresarial (FREITAS, 2015a, s/p).

Não obstante, no mesmo ano é iniciado o movimento de formulação da BNCC para toda a educação básica, constituindo um campo acirrado de disputas entre setores privados, o que será aprofundado na próxima seção.

Avançando no tema, em 2016, no Governo Michel Temer, o projeto de esvaziamento do ensino médio é colocado em curso de forma acentuada. O lançamento do documento $A$ Travessia Social, desdobramento da formulação anterior Ponte para o Futuro, implicou importantes alterações para a economia e a área social, afetando a educação, principalmente nos aspectos do currículo e financiamento do ensino médio. As mudanças promovidas no referido documento repercutiram na edição da MP n. 746/2016 - que regulamentou a reforma dessa etapa de ensino.

O caráter de urgência em que se apresentou o tema da reforma do ensino médio, através de medida provisória, demonstrou a necessidade de se apressar um projeto de educação capaz de agregar os interesses que se apregoavam no campo econômico. Tal urgência evidenciou também a total falta de diálogo do Governo com o restante dos setores da Sociedade, detentores de interesses contrários. 
Destaca-se, nesse bojo, a aprovação da PEC n.55, transformada em Emenda Constitucional n.95, em dezembro de 2016. Essa Emenda estabeleceu alterações no regime fiscal do país, congelando o investimento público em áreas sociais, por um período de vinte anos. Relacionando-a ao projeto de reforma do ensino médio, Motta e Frigotto (2017), consideram que há em curso uma abertura para privatização dessa etapa de ensino, haja vista a inviabilização de recursos para a estruturação das mudanças dirigidas às escolas de ensino médio não profissional (MOTTA; FRIGOTTOT, 2017).

Embora a MP n. 746/2016 tenha sido amplamente criticada por diversos setores ${ }^{6}$ relacionados à educação, além de ser alvo de um amplo movimento de resistência, representado pelo expressivo número de escolas estaduais e universidades ocupadas por estudantes, ela foi transformada em Lei n. 13.415, no início de 2017. Essa Lei consumiu, quase que integralmente, as alterações previstas na MP n. 746/2016 e, alterou o texto da LDBEN/1996, nos seguintes aspectos: criação de escolas de ensino médio em tempo integral; divisão do currículo em formação básica comum, garantida pela BNCC, e outro dividido em cinco itinerários formativos - Linguagens e suas Tecnologias; Matemática e suas Tecnologias; Ciências da Natureza e suas tecnologias; Ciências Humanas e suas tecnologias, e Formação Técnica e Profissional, podendo o estudante escolher apenas uma delas; definição de até 1800 horas para a carga horária total da Formação Básica Comum; extensão da jornada para cinco horas diárias; definição de uma carga horária mínima anual de 3.000 horas; organização de um modelo de estudos e práticas para contemplar as disciplinas de Filosofia, Sociologia, Artes e Educação Física; contratação por notório saber para docência no itinerário formativo relativo à Formação Técnica e Profissional; abertura para o estabelecimento de convênios entre os sistemas de ensino e instituições de educação à distância para a oferta de cursos a serem integralizados à carga horária total do ensino médio, e abertura para o estabelecimento de parcerias com o setor privado para oferta do itinerário formativo relativo à Formação Técnica e Profissional (BRASIL, 2017).

A BNCCEM, por conseguinte, apresenta-se como importante contributo para o cumprimento das alterações no ensino médio definidas na Lei n. 13.415/2017, complementando, assim, o projeto de educação instituído no país, que consiste em esvaziar a formação dos estudantes. Como mencionado anteriormente, o processo de elaboração da BNCC ocorreu a partir de 2015, sendo sua importância citada no documento Pátria Educadora. Na seção seguinte, o tema será detalhado, buscando elucidar os elementos que a constituíram e que contribuem para a análise do modelo de ensino médio apresentado no cenário nacional.

\section{CONSTRUÇÃO DA BNCC DO ENSINO MÉDIO}

A configuração de um projeto de ensino médio no país constitui um campo de acirradas disputas, principalmente por parte dos setores privados. Ao longo dos anos, tem se desenhado um estreitamento, cada vez maior, entre educação e economia, sendo a escola transformada em um vetor mercadológico, por meio da qual se busca aumentar as taxas de lucratividade das grandes corporações educacionais e a construção de "subjetividades individualistas, meritocráticas, assim como o desenvolvimento de habilidades técnicas" (CURY; REIS; ZANARDI, 2018, p. 64). Esses objetivos são evidenciados na trajetória das políticas curriculares dirigidas ao ensino médio desde a implantação da DCNEM/1998 e que, na atualidade, se expressa por meio da definição da BNCC.

A presença de setores privados atuando junto à administração pública não é recente e o estudo da história da educação comprova que a tensão entre os setores privados e publicistas surge com a estatização da educação que, no Brasil, ganha expressão a partir das décadas de 1920 e 1930, e perdura até a atualidade a partir de diferentes argumentos e intensidades. A partir da década de 1990, muitas foram as investiduras para que esses setores privatistas ganhassem espaço em áreas, até então, exclusivas do Estado, como o caso da educação. A abertura concedida ao privado, por meio da reforma Bresser-Pereira,

\footnotetext{
${ }^{6}$ Destacam-se: Associação Nacional de Pós-Graduação e Pesquisa em Educação (ANPED); Confederação Nacional dos Trabalhadores em Educação (CNTE); Sindicato Nacional dos Docentes das Instituições de Ensino Superior (ANDES-SN); União Brasileira dos Estudantes (UNE); União Brasileira dos Estudantes Secundaristas (UBES), dentre outras. 
possibilitou que grandes empresários, a partir da justificativa de busca pela qualidade educacional, colocassem em pauta seus projetos para o ensino público do país, principalmente no tocante ao currículo e avaliação.

Em 2006, o estreitamento entre público e privado se intensifica com a criação do Movimento Todos pela Educação (MTPE), que consegue, por meio de suas articulações, inserir suas pautas na arena política educacional, obtendo como um de seus resultados a implantação do Plano de Desenvolvimento da Educação (PDE), por meio do qual se instituiu o Plano de Metas: Compromisso Todos pela Educação.

Por pressão desse Movimento, entra em pauta a definição de "direitos e aprendizagens" para a constituição de um projeto nacional de currículo para toda a educação básica no Plano Nacional de Educação (PNE), aprovado em 2014. Ainda que a referência de currículo único para todo território brasileiro já estivesse contemplada nos textos da Constituição Federal/1988 e da LDBEN/1996, é no PNE/2014 que ela se apresenta com maior clareza. Com base em suas definições, o processo de elaboração da BNCC é iniciado em 2015 - com a articulação do Movimento pela Base Nacional Comum (MBNC).

Esse Movimento foi criado em 2013 e constituído por representantes vinculados a instituições públicas - União Nacional de Dirigentes Municipais (UNDIME), Conselho Nacional de Secretários de Educação (CONSED), Conselho Nacional de Educação (CNE), Comissão de Educação da Câmara de São Paulo (CEE/SP); e ainda instituições privadas, com a presença de grandes empresas, como a Fundação Lemann. Sobre essas instituições, chamadas de parceiras pelos agentes públicos, Peroni e Caetano (2014) sinalizam a problemática que tal ação tem representado para a educação pública, haja vista as pautas afirmadas nos projetos educacionais tais como promoção do individual, da meritocracia, da inovação, da flexibilização, da eficiência e eficácia - termos constitutivos da própria lógica de mercado.

$\mathrm{Na}$ concepção dos entusiastas e formuladores da BNCC, a implantação do currículo comum a todo território nacional corresponde a uma medida essencial para o alcance da pretendida qualidade do ensino público, bem como para a superação das desigualdades escolares que assolam o país, principalmente nos contextos sociais mais vulneráveis. O Brasil será igual de ponta a ponta, assim destacou Mendonça Filho, Ministro da Educação, ao referir-se sobre a Base. Considera-se, no discurso desses, a definição de conteúdos idênticos a todos, uma estratégia para proporcionar maior igualdade de oportunidades entre os estudantes.

Contudo, a definição de padrões curriculares em nível nacional, desconsiderando as particularidades locais, seus valores e suas culturas, como também a diversidade dos sujeitos e de suas formas de vivenciar as infâncias e juventudes, reforça o desrespeito com as multiplicidades que envolvem não somente a escola, mas a sociedade como um todo, retirando a possibilidade de uma formação para o exercício da liberdade e da autonomia (SILVA, 2015). Desse modo, a definição da Base não é capaz de superar as desigualdades escolares, ao contrário, tem grandes chances de intensificá-las.

A BNCC, ao tratar de qualidade educacional, está interessada na melhoria dos resultados das avaliações externas e, por sua vez, do Índice de Desenvolvimento da Educação Básica (IDEB). As competências e habilidades preconizadas em seu texto pouco correspondem à formação humana dos estudantes, ao ideal de propiciá-los uma educação crítica e significativa, e sim, ao estreitamento entre o que se ensina e o que se avalia para, desse modo, melhorar o ranking do país no contexto internacional. Ao analisar o texto da Base observa-se a definição de códigos para cada competência e habilidade listada. Essa definição pode ser compreendida como "adequação às estruturas de avaliação, ranqueamento e responsabilização", contribuindo para maior controle dos resultados dos estudantes e do trabalho do professor (PINTO, 2018, p. 116).

A investidura do MEC em construir confiabilidade social quanto à BNCC foi muita, a se destacar o alto investimento em propagandas midiáticas associadas à construção de um imaginário de obra coletiva por meio da abertura de consultas públicas - instrumento pelo qual o Governo Federal constrói a ideia de participação social, democratização dos processos de construção de políticas, envolvendo a Base sobre a roupagem de documento elaborado por todos, para todos.

As versões finais da Base para as etapas da educação infantil e ensino fundamental foram apresentadas em 2017. No caso do ensino médio, o texto contou com um período maior para sua elaboração tendo em vista abarcar as definições presentes na Lei 13.415/2017, sendo apresentada em abril de 2018. 
A BNCC do ensino médio (BNCCEM) é um documento normativo que estabelece um conjunto de aprendizagens essenciais que devem ser desenvolvidas com base em conhecimentos, competências e habilidades (BRASIL, 2018). É mantida a noção de competências, bem como a concepção de flexibilização conforme apresentado nas DCNEM/1998. Essa não é uma noção empregada somente ao ensino médio, sendo observada uma lista de competências e habilidades desde a educação infantil, contudo a flexibilização curricular se configura na última etapa da educação básica nos chamados itinerários formativos. A aplicabilidade das competências associada à flexibilização curricular cumpre o papel de direcionamento da formação escolar às dimensões técnica e instrumental. Como salientado por Silva (2018), a BNCCEM corrobora para uma educação imediatista, estritamente voltada aos resultados e que possibilita maior controle sobre as vivências individuais dos estudantes, e sobre as instituições escolares.

A BNCCEM, embora não seja apresentada como currículo, se configura como tal à medida em que sua implementação é imposta aos Estados e Municípios a partir da reformulação de seus planos curriculares. Silva (2018), sobre este currículo pensado e elaborado fora dos contextos escolares afirma a sua dimensão autoritária e destaca sua concepção tradicional que se baseia em encontrar fora da escola as resoluções para os seus problemas. Nessa direção, aos professores é ofertado o papel de adequação, retirando-lhes a capacidade de refletir criticamente sobre seu trabalho e elaborar seus planos pedagógicos conforme suas demandas locais.

Mediante a destituição da autonomia docente, portanto, abre-se um espaço amplo, fecundo e diversificado para o mercado educacional, envolvendo, como citado anteriormente, a produção e comercialização de material didático e instrucional, equipamentos, plataformas, sistemas, softwares, entre outros, promissores aos anseios de obtenção de altas taxas de lucratividade no setor educacional, em que o Ensino a Distância (EaD) desempenha papel fundamental, e que se aprofunda de forma significativa, no contexto da pandemia da Covid-19, por meio do Ensino Remoto Emergencial (ERE).

Vale destacar que, segundo afirma Hypólito (2021), o contrato firmado entre a Fundação Lemann e a Google, contou com um investimento na casa dos milhões, para o oferecimento de vinte e cinco mil planos de aulas prontos para professores. Esses planos são elaborados a partir de práticas de ensino e conteúdos considerados relevantes por essas instituições privadas, fundamentando-se na concepção das boas práticas em que se validam as reformas educacionais, sobretudo a reforma curricular imposta pela Base. Haja vista a sobrecarga de atividades em que muitos docentes se encontram, intensificada pelos modelos de trabalho impostos pela pandemia, tais planos acabam sendo consumidos por parte de alguns professores.

Em síntese, a Base instituída nacionalmente se atém a uma formação assentada na aplicabilidade do conhecimento, em sentido restrito e imediatista. Segundo Silva (2018, p.12), "uma vez reduzida à aplicação, ao imediato, reforça-se a ideia de que o conhecimento se limita a dar respostas imediatas às situações-problema do dia a dia, e se impede que se tome o conhecimento como objeto de experiências que oportuniza a reflexão e a crítica". A implantação da Base ainda exige professores que sejam empreendedores para, assim, formar estudantes empreendedores, que corresponderão às novas definições impostas pela Reforma Trabalhista em curso no Governo Bolsonaro.

\section{ATUAL PLANO CURRICULAR PARA O ENSINO MÉDIO EM MINAS GERAIS: APONTAMENTOS INICIAIS}

As principais políticas educacionais dirigidas ao ensino médio nacionalmente, encontraram, no Estado de Minas Gerais, terreno fértil para a sua implantação, desde os anos de 1990, com o projeto reformador da educação no país. O estudo realizado por Melo e Duarte (2011) aponta essa constatação, ressaltando as políticas, programas e projetos desenvolvidos no contexto mineiro no decorrer dos governos, levando à compreensão de que Minas Gerais sempre assumiu, sem qualquer resistência por parte do poder público, os projetos estruturados para a educação em nível nacional.

Atualmente, na gestão do empresário Romeu Zema (Partido Novo) é colocado em curso o novo ensino médio, a partir do Currículo Referência de Minas Gerais. A parte relacionada à última etapa da educação básica baseia-se nas definições da Lei n. 13.415/2017 e da BNCCEM. 
A elaboração do referido documento iniciou-se em julho de 2019, a partir das premissas de ampliação do tempo de permanência na escola, garantia dos direitos de aprendizagem e desenvolvimento do protagonismo juvenil. Mediante aprovação da Portaria MEC n. 268/2018 foi estabelecido um comitê nacional para implantação da BNCC nos Estados. No caso mineiro, se formou uma equipe constituída por um coordenador de currículo, um coordenador para a etapa do ensino médio, quatro coordenadores de áreas do conhecimento, dezoito redatores formadores e dois articuladores de itinerários. Essa equipe integrou o Programa de Apoio à Implementação da BNCC (PROBNCC), sendo firmada em regime de colaboração entre a UNDIME/MG e Secretaria de Estado de Minas Gerais (SEE/MG). A escolha de cada integrante para os cargos mencionados ocorreu por meio de seleção conjunta entre as referidas Instituições, a partir de critérios de mérito e representatividade da diversidade do território (MINAS GERAIS, 2020, s/p).

Observa-se que a Base Nacional, embora não se constitua enquanto currículo nos discursos oficiais, seu conteúdo tem sido imposto aos Estados e Municípios no conteúdo de seus planos curriculares. A investidura para a sua implantação é revelada por articulações nacionais, que fomentaram a Portaria MEC n. 268/2018 que institui o Comitê Nacional e, por conseguinte, origina o Movimento PROBNCC. A reforma curricular posta pela BNCC é assegurada por diversos mecanismos de modo a garantir sua aplicação local, e com isso, garantir o projeto junto às grandes empresas.

Assim como realizado no processo de elaboração da BNCC, o Estado de Minas Gerais, na figura da SEE/MG abriu consultas públicas online para a participação de professores, estudantes e demais membros da sociedade no texto preliminar do Currículo Referência. Também foi realizado o chamado Dia $D$ que se configurou como um dia para participação exclusiva dos estudantes matriculados no ensino médio no Estado. A escuta desses jovens ocorreu mediante questionário online, contando com um contingente de 151.415 contribuições, distribuídas em 3.571 escolas.

Aparentemente, a consulta pública democratiza a participação dos sujeitos-alvo na construção das políticas públicas, no entanto é necessário analisar com profundidade esse processo a fim de compreender os métodos, a estrutura, e as análises dos resultados. Isso porque, no caso da BNCC, os discursos oficiais e midiáticos elucidaram forte participação social na elaboração de seu texto, gerando a ideia de construção efetivamente coletiva dessa política. Em contrapartida, o que se observou na prática foi uma participação limitada.

Apesar de os números relativos às contribuições sociais ao texto da Base terem se mostrado expressivos, chegando a 12 milhões no total, o estudo de seus dados revelou que o processo contribuiu "muito mais como legitimador dos discursos oficiais sobre participação do que, propriamente, produtor de participação social efetiva" - "os vícios metodológicos e a insuficiência na análise de seus resultados por parte do MEC afastaram a consulta dos fins para os quais ela foi supostamente concebida” (CÁSSIO, $2017, \mathrm{~s} / \mathrm{p})$.

O que se observa é a utilização de métodos como esse, de consultas públicas, no âmbito da formulação de uma política pública, muito mais voltada para gerar um imaginário de obra coletiva do que um processo realmente endereçado à escuta e participação ativa dos sujeitos-alvo dessa política. Com esse imaginário, os números são difundidos pela mídia, e os discursos oficiais são legitimados.

Quanto à fase de elaboração final do documento curricular do Estado, vale ressaltar a parceria estabelecida com o Instituto Reúna, caracterizado como organização sem fins lucrativos. Segundo informações em seu site, o Instituto surge a partir da homologação da BNCC tendo como objetivo contribuir para a implementação da Base e para o cumprimento da Meta 7, do PNE/2014-2024, que se refere à qualidade da educação básica.

Chama atenção o seguinte trecho retirado do site $^{7}$ : "O Instituto Reúna desenvolve conhecimentos técnicos e pedagógicos para o ensino e aprendizagem, e contribui para tornar o sistema educacional mais coerente". De maneira complementar, apontam atuar em quatro frentes, a saber: formação, material didático, currículo e avaliação a partir da construção "de ferramentas e conteúdos alinhados à BNCC, reunindo o que há de melhor nas experiências e referências nacionais e internacionais e potencializando uma rede de parceiros para atuar na transformação da educação".

\footnotetext{
${ }^{7}$ Informação retirada do site do Instituto Reúna, disponível no link: https://institutoreuna.org.br/o-reuna/. Acesso em 15 de abril de 2021.
} 
Diante desse trecho cabe retomar que a BNCC foi elaborada tendo como principais interlocutores grupos e instituições vinculadas ao MTPE e outras fundações e entidades, com ou sem fins lucrativos. É importante considerar que a presença dessas organizações na disputa por um currículo comum a todo território nacional expressa o interesse no mercado educacional que vem se construindo fortemente no país.

Freitas (2015b, s/p), assim que se iniciou a formulação do texto da BNCC, considerava a abertura para a privatização da educação, ressaltando que ao se constituir um modelo de currículo dessa natureza, constituiria também "uma base mercadológica para atuação de consultorias, empresas de avaliação, assessorias e produtoras de material didático e midiático em grande escala". Desse modo, apontava que essas instituições privadas atuariam, em primeiro momento, na formulação do conteúdo curricular para, depois, assumirem o papel de administradoras dessa política. Verifica-se que seu alerta estava correto.

A partir da Base elaborada e implantada, empresas como o Instituto Reúna atuam no âmbito da educação pública com a venda de seus serviços "mágicos" para as redes de ensino, escolas e professores. A parceria estabelecida pelo Governo de Estado de Minas Gerais com uma organização dessa natureza para "leitura crítica" de um plano de currículo que tem como premissa atender as definições da política curricular nacional, e aponta-nos o caminho pelo qual esse mercado educacional vem se estruturando e fortalecendo.

A versão final do documento foi aprovada em abril de 2021, e define as configurações do novo ensino médio no Estado, que passa então a se dividir entre: formação geral básica e cinco itinerários formativos. A carga horária anual é ampliada de 2.400 horas para 3.000 horas, sendo distribuídas 1.800 horas para o cumprimento da base geral e 1.200 horas para o cumprimento dos itinerários formativos. Essa ampliação deverá ser assumida pelas escolas de ensino médio até 2022.

Para a oferta dos itinerários formativos é definido que sua organização ocorrerá conforme o Projeto Político e Pedagógico das escolas e os recursos disponíveis, e de acordo com as orientações das redes de ensino. Os estudantes poderão escolher entre os itinerários disponíveis em seu Município de residência, podendo ainda percorrer mais de um. A Lei n.13.415/2017 e a BNCCEM definem cinco itinerários formativos, sendo quatro relacionados às áreas do conhecimento: Linguagem e suas Tecnologias; Matemática e suas Tecnologias; Ciências da Natureza e suas Tecnologias e Ciências Humanas e suas Tecnologias; e um quinto itinerário responsável pela Formação Técnica e Profissional. Essas definições são mantidas para a REE/MG, sendo acrescida a informação de possíveis combinações entre mais de uma área do conhecimento direcionada a atenção para o mundo do trabalho.

Os itinerários formativos, no Estado, também perpassam por duas unidades curriculares: Projeto de Vida e Eletivas. O primeiro possui como objetivo "o desenvolvimento da capacidade de autoconhecimento, de potencialidades, aspirações, interesses e objetivos de vida" (MINAS GERAIS, 2021, p. 45-46) dos estudantes matriculados no ensino médio. Já as Eletivas se constituem como aulas, com enfoque em temas variados, que os estudantes poderão cursar integradas à área do conhecimento escolhida ou formação técnica de acordo com seu interesse individual, associando ainda mais de uma área. Esse formato de aula, segundo o documento curricular do Estado, tem como objetivo pautar-se em uma abordagem que enfatiza a experiência prática com vistas à ampliação da percepção de mundo dos jovens, o fortalecimento da autonomia e o protagonismo juvenil.

O documento curricular, base para o novo ensino médio na REE/MG, aparentemente mostra-se atrativo ao abarcar em seu texto as diversidades que envolvem não somente os estudantes, mas as experiências sociais que constituem o território mineiro. Ao tratar sobre os itinerários formativos é interessante pensar em uma formação fundamentada em uma educação escolar que se atente para as múltiplas dimensões que contemplam uma formação significativa e voltada para a autonomia, análise crítica e protagonismo social. Contudo, há de se considerar alguns pontos.

$\mathrm{Na}$ parte destinada à concepção e proposição do quinto itinerário, Formação Técnica e Profissional, o documento se atenta às mudanças no mundo do trabalho e cita o estudo intitulado O futuro do trabalho elaborado pelo Fórum Econômico Mundial, em 2016, onde são apresentadas as habilidades consideradas essenciais a partir de 2020. Em sequência, avalia ser necessário o alinhamento do currículo às novas demandas que são requeridas pelas transformações do trabalho, na formação dos estudantes. 
Observa-se que, ao mesmo tempo em que o plano curricular do Estado referencia o trabalho em uma perspectiva educativa ${ }_{2}$ também referencia competências e habilidades que se atêm mais à aplicabilidade prática do que reflexão crítica sobre o trabalho e suas transformações.

Conceitos como flexibilidade, inovação e empreendedorismo sustentam a base dessa formação, direcionando o foco para a constituição de sujeitos aptos ao mercado de trabalho, que correspondam ao perfil requerido: trabalhadores criativos, inovadores e flexíveis às mudanças, como também, trabalhadores empreendedores. Nesse sentido, ao enfatizar a Formação Técnica e Profissional, o documento curricular de Minas Gerais salienta que "as exigências de novas competências e habilidades para atuar no mundo do trabalho de forma proficiente mostram o quanto a formação escolar precisa se reorganizar a partir de princípios inovadores e flexíveis” (MINAS GERAIS, 2021, p. 340-341).

Cabe destacar na Lei n. 13.415/2017, que institui a atual configuração nacional para o ensino médio, a abertura para o estabelecimento de parcerias entre setor público e instituições privadas para a oferta dos itinerários formativos. Mediante as condições estruturais das escolas da REE/MG, onde muitas não possuem laboratório de ciências e informática, tampouco equipamentos digitais, pode-se considerar que a oferta dessa parte da formação flexível ocorrerá a partir dessas parcerias, sobretudo no que tange a Formação Técnica e Profissional. Além disso, cabe refletir se, de fato, os estudantes terão a garantia de escolha desses itinerários conforme seus anseios individuais, haja vista as possibilidades desse novo ensino médio se assemelhar às experiências do Reinventando o Ensino Médio (REM/MG), no qual entre o discurso oficial e as possibilidades garantidas concretamente ocorreu um grande abismo.

Esse Projeto foi criado em 2012 caracterizando-se como um desdobramento do PROEMI, e possuía como objetivos o combate à evasão escolar através da reformulação curricular e a criação de ciclos de estudos com identidades próprias voltadas a proporcionar melhores condições aos estudantes de ensino médio para a continuidade dos estudos e de empregabilidade ao fim da etapa de ensino. No que tange ao currículo, o REE/MG ampliou a carga horária anual para 3.000 horas, como mencionado, sendo parte destinada às denominadas áreas de empregabilidade. Avaliada sua implementação, o referido Projeto não considerou as condições estruturais das escolas, não havendo contratações de profissionais especializados para atuar na condução das áreas de empregabilidade e, tampouco para sua coordenação, ampliando de modo significativo a carga horária de trabalho dos professores. Além disso, iniciou-se um processo de parceria público-privada para a oferta das áreas de empregabilidade, reduzindo ainda a escolha do estudante a partir de sua expansão na REM/MG (FIGUEIREDO, 2015).

Com relação aos itinerários formativos definidos para o novo ensino médio, há de se analisar como será sua constituição na prática, a partir de sua trajetória de implementação e condução. Não se pode perder de vista que, com a aprovação da Emenda Constitucional n.95/2016, os investimentos nas políticas públicas, dentre elas a educação, estão impossibilitados por um prazo de vinte anos. O que nos leva à reflexão de: como esse modelo de ensino será assegurado no Estado, a partir de quais condições materiais? A hipótese para essa questão é a entrada do setor privado como principal mantenedor da oferta desses itinerários e, ainda, a destinação de estudantes, principalmente os das escolas mais vulneráveis à Formação Técnica e Profissional.

Ressalta-se que o Governo de Minas Gerais vem estudando a implantação de escolas públicoprivadas em 2021. Esse modelo, conhecido como Charter Schoot, no contexto americano, representa a terceirização da educação pública através da concessão da gestão da escola à iniciativa privada. Pretendese aplicar esse modelo em quatro escolas do Estado, e se colocado em prática há uma grande tendência para a sua ampliação na REE/MG. A exemplo das experiências do Chile, que empregou esse modelo, o que se obteve como resultado foi o deslocamento de recursos públicos para bolsos de empresários, contribuindo para o lucro desses e a deterioração da qualidade educacional. Assim, se concretizada no contexto mineiro, se constituirá um imenso "desastre" tanto para a formação dos estudantes quanto para o trabalho dos professores.

Quanto à formação de professores, o atual documento curricular destaca a adequação da formação inicial às configurações do novo ensino médio como ação necessária, apontando que protagonismo estudantil, educação integral, transversalidade e flexibilidade do currículo são conceitos que devem constituir-se como centro. Por conseguinte, ressalta como ação a "articulação com

\footnotetext{
${ }^{8}$ Sobre o tema ver Freitas (2012).
} 
Instituições de Ensino Superior e os Institutos Federais no sentido de adaptarem os currículos dos cursos de licenciaturas para atenderem às especificidades da formação de seus estudantes, futuros professores do ensino médio" (MINAS GERAIS, 2021, p. 425).

Nesse ponto, vale destacar que a presença dos setores privados na formulação de políticas de educação tem constituído, cada vez mais, conteúdos voltados a atender seus interesses econômicos que repercutem também sobre a formação de professores. Ora, a partir do momento em que é imposta às escolas uma lista de competências e habilidades contidas em uma Base Curricular Nacional, construídas fora de seu contex to local, se evidencia o mecanismo pelo qual passa a ser controlado não somente o que se ensina, mas também como se ensina. Buscando alcançar melhores resultados nas avaliações externas, do IDEB, o currículo é estruturado e junto a ele tem-se um conjunto de instrumentos para se atingir suas pretensões. Nesse cenário, a formação inicial de professores também é alvo de tentativas constantes de reformulações, com vistas a completar o projeto de educação em curso.

O atual plano curricular de Minas Gerais contempla o conteúdo da Base e reforça esse olhar sobre a formação docente, induzindo uma experiência voltada para a aplicabilidade prática dos conteúdos das políticas, em detrimento do conhecimento como objeto de reflexão, análise crítica e pesquisa. No que corresponde à formação continuada, o documento aponta a estruturação de um processo de aperfeiçoamento, atualização e aprofundamento de conhecimentos relacionados aos componentes do novo ensino médio, que se constitui da formação básica geral e de itinerários formativos. Para tanto, essa formação vem sendo planejada a partir das seguintes premissas:

Produção de materiais de orientação prática para os professores (cadernos pedagógicos), pautados nas metodologias ativas e que considere as experiências próprias da rede;

Desenvolvimento de programas específicos de formação continuada de educadores para o desenvolvimento dos itinerários formativos;

Adequação com base no Currículo Referência dos cursos e ações formativas destinadas aos profissionais da educação;

Aspectos de interdisciplinaridade estabelecidos nas DCNEM e na BNCCEM (MINAS GERAIS, 2020, s/p).

Diante do exposto, considera-se em curso um projeto bem orquestrado em prol do esvaziamento da educação pública no país, com abertura cada vez maior para a sua privatização. No caso do ensino médio, as reformas postas pela Lei n.13.415/2017 e pela BNCCEM configuram-se como instrumentos que conduzirão milhares de estudantes de escolas públicas ao abismo, haja vista uma formação que não os preparará para o trabalho, tampouco para as universidades. $\mathrm{Na}$ verdade, os preparará para assumirem postos de trabalho destituídos de direitos e o autoemprego, atualmente denominado empreendedorismo - que poderá reverberar no Estado de Minas Gerais através de seu atual plano curricular.

Vale afirmar os intensos retrocessos sociais promovidos pelo Governo Bolsonaro, que retomam, de modo acentuado, a reforma administrativa de FHC/1995, por meio de propostas de emendas constitucionais, como a de número 32/2020 que tramita na Câmara dos Deputados, bem como o conjunto de medidas já instituídas como a aprovação da reforma trabalhista, reforma da previdência e Lei da terceirização irrestrita. Observa-se um Governo que retira direitos da população e concentra renda para ser transferida a bancos ajudando-os a se manterem bilionários. No que corresponde à educação pública, pouquíssimos investimentos públicos e muita atenção por parte das instituições privadas, como sinalizado ao longo do texto. O olhar dessas organizações sobre a escola pública se justifica pela necessidade quanto à formação de empreendedores, que contribuirão com seus interesses, por isso a disputa pela Base Curricular - que impõe um perfil de professor empreendedor, que conduzirão estudantes empreendedores, flexíveis, criativos e inovadores em um contexto de altos índices de desemprego e informalidade, e total destituição de direitos sociais.

A título de finalização destaca-se que o novo ensino médio em Minas Gerais iniciou em 2020, com a adoção de onze escolas-piloto, escolhidas segundo critérios definidos na Portaria MEC n. 1024/2018, a saber: (1) escola que atenda a educação escolar indígena, quilombola ou educação do campo; (2) que atenda estudantes de ensino médio regular noturno; (3) escola que apresente indicador de nível 
socioeconômico baixo ou muito baixo; (4) escola que seja a única a oferecer ensino médio em seu município; e (5) escola que tenha até 130 estudantes matriculados no ensino médio. Além desses critérios definidos pela Portaria mencionada, o grupo de escolas-piloto foi constituído a partir das diferentes regiões que compõem o Estado: Jequitinhonha-Mucuri; Central; Alto Paranaíba; Norte; Triângulo e Sul de Minas. Posteriormente, dado o período de experiência dessas escolas, o novo ensino médio será ampliado a todas as escolas da REE/MG.

Ressalta-se que essas escolas-piloto selecionadas no ano de 2020 mantiveram suas atividades de implantação do projeto mediante ajustes necessários ao contexto atual imposto pela Pandemia, permanecendo o trabalho com estudantes em Regime Especial de Atividades Não Presenciais (REANP); isso corresponde ao ERE, já citado, em desenvolvimento nas universidades públicas brasileiras diante da Covid-19.

\section{CONSIDERAÇÕES FINAIS}

A análise da concepção e do sentido do conjunto das políticas curriculares dirigidas ao ensino médio no Brasil permite constatar que estas apresentaram mudanças substanciais nas formas de conceber a formação dos estudantes, essencialmente os mais pobres. No decorrer das políticas de currículo instituídas se observa, com nitidez, o projeto que vinha se constituindo ao redor do ensino médio e o seu alinhamento às demandas econômicas. Atualmente, com a aprovação da Lei n. 13.415/2017 e da BNCCEM, se colocou em curso um projeto de educação de ensino médio mais voltado para a aquisição de competências e habilidades, delegando à formação o papel imediatista, com respostas rápidas às demandas, situações-problema, colocadas pela economia e pelo setor produtivo. Com isso, é deixada à margem a concepção de uma educação verdadeiramente voltada ao conhecimento como objeto da reflexão crítica, promotora de autonomia e liberdade ativas.

Tal projeto imprime controle não somente à formação dos estudantes, mas da escola e de seu professorado. Além disso, imprime repercussões para a própria formação inicial de professores, evidenciando um perfil de docente criativo e inovador, programado para atender as expectativas dos formuladores das políticas públicas de educação. Vem se construindo através da reforma curricular posta pela Base um perfil de professor voltado à aplicação de seu conteúdo, em detrimento de um docente pesquisador, reflexivo, que constrói o seu próprio trabalho.

No caso do novo ensino médio em curso no Estado de Minas Gerais, por meio da homologação do atual plano curricular, ainda é cedo para se analisar o curso ao qual se destinará na prática e seus resultados concretos. As reflexões apresentadas neste estudo pautaram-se na apresentação de elementos considerados importantes para a compreensão do conteúdo do currículo definido para a REE/MG, e de suas articulações com o texto da Lei n.13.415/2017 e da BNCCEM. A partir das reflexões realizadas considera-se que a ambos os documentos nacionais mencionados são contemplados na elaboração do plano de currículo estadual, havendo tendência à privatização do ensino médio na figura de plataformas de ensino, material didático, consultorias, bem como no estabelecimento de parcerias público-privadas para a oferta dos itinerários formativos, principalmente do quinto itinerário responsável pela Formação Técnica e Profissional.

Considera-se ainda que, embora o Currículo Referência de Minas Gerais contemple o discurso das juventudes e das diversidades como eixos centrais da formação com vistas a uma educação mais significativa, outros discursos presentes no mesmo documento conflitam com esse objetivo, sobretudo no que corresponde à parte flexível do percurso formativo.

Pelo presentismo do tema, considera-se que este estudo requer continuidade. O tema precisa ser aprofundado mediante pesquisas empíricas, tendo em vista melhor compreender o campo de formulação desse plano curricular, suas articulações políticas, bem como sua implementação nas escolas, e as percepções dos sujeitos que a compõem: professores, gestores, estudantes e famílias. Esse aprofundamento deve contemplar ainda os efeitos do REANP, desenvolvido a partir da pandemia da Covid-19, e a reforma administrativa em tramitação no Congresso Nacional que, se aprovada, determinará a extinção de direitos trabalhistas fundamentais dos servidores públicos, em especial, dos professores tais como a estabilidade. 


\section{REFERÊNCIAS}

APPLE, Michael Whitman. A política do conhecimento oficial: faz sentido a ideia de um currículo nacional? In: MOREIRA, Antônio Flávio; SILVA, Tomaz Tadeu da (Orgs.). Currículo, cultura e sociedade. 8. ed. São Paulo: Cortez, 2005. p. 71-106.

APPLE, Michael Whitman.Ideologia e currículo. Trad. Vinicius Figueira. 3 ed. Porto Alegre: Artmed, 2006.

BRASIL. Lei n. 13.415, de 16 de fevereiro de 2017. Altera a Lei que estabelece as diretrizes e bases da educação nacional e a Lei que regulamenta o Fundo de Manutenção e Desenvolvimento da Educação Básica e de Valorização dos Profissionais da Educação, e institui a Política de Fomento à Implementação de Escolas de Ensino Médio em Tempo Integral. Diário Oficial da União, Brasília, DF, 17 fev. 2017.

BRASIL. Base Nacional Comum Curricular do ensino médio. Ministério da Educação, Brasília, DF, 14 dez. 2018.

CÁSSIO, Fernando. Participação e Participacionismo na construção da Base Nacional Comum Curricular. Jornal NEXO [online], 2 de dezembro de 2017. Disponível em: $<$ https://www.nexojornal.com.br/ensaio/2017/Participa\%C3\%A7\%C3\%A3o-e-participacionismo-naconstru\%C3\%A7\%C3\%A3o-da-Base-Nacional-Comum-Curricular> Acesso em: 15/04/2021.

CURY, Carlos Roberto Jamil; REIS, Magali; ZANARDI, Teodoro Adriano Costa. Base Nacional Comum Curricular: dilemas e perspectivas. São Paulo: Cortez Editora, 2018.

FIGUEIREDO, Lorene. Ensino Médio e Formação Humana: quando a inovação se apresenta como retrocesso. Revista Poiésis, Unisul, Tubarão, v. 10, n. 17, p. 54-84, jan./jun. 2015.<http://dx.doi.org/10.19177/prppge.v10e17201654-84>

FREITAS, Luiz Carlos de. Os reformadores empresariais da educação: da desmoralização do magistério à destituição do sistema público de educação. Educação e Sociedade, Campinas, v. 33, n. 119, p. 379404, abr./jun. 2012. https://doi.org/10.1590/S0101-73302012000200004

FREITAS, Luiz Carlos de. Pátria Educadora III. Avaliação Educacional - Blog do Freitas, Campinas, SP, 11 mar. 2015a. Disponível em: < https://avaliacaoeducacional. com/2015/04/24/patria-educadoraiii/> Acesso em: 10/04/2021.

FREITAS, Luiz Carlos de. Base nacional (mercadológica) comum. Avaliação Educacional - Blog do Freitas, Campinas, SP, 20 de jul. 2015b. Disponível em: $<$ https://avaliacaoeducacional.com/2015/07/20/base-nacional-mercadologica-comum/> Acesso em: 10/04/2021.

HYPÓLITO, Álvaro Moreira. BNCC, agenda global e formação docente. Revista Retratos da Escola, Brasília, v. 13, n. 25, p. 187-201, jan./maio. 2019. < http://dx.doi.org/10.22420/rde.v13i25.995> Acesso em: 10/04/2021.

HYPÓLITO, Álvaro Moreira. Lançamento da Plataforma Entre Docentes. Evento online, 3 de maio de 2021, disponível em: < https://www.youtube.com/ watch?v=IOl5fvFwc54>. Acesso em 03 de maio de 2021. 
KRAWCZYK, Nora. Ensino Médio: empresários dão as cartas na escola pública. Educação e Sociedade, Campinas, v. 35, n. 126, p. 21-41, jan./mar. 2014. <https://doi.org/10.1590/S0101$73302014000100002>$

MELO, Savana Diniz Gomes; DUARTE, Adriana Maria Cancela. Políticas para o Ensino Médio no Brasil: perspectivas para a universalização, Caderno Cedes, Campinas, v. 31, n. 84, p. 231-251, maio/ago. 2011. <https://doi.org/10.1590/S0101-32622011000200005>

MINAS GERAIS. Currículo Referência de Minas Gerais. 2021. Disponível em: $<$ http://basenacionalcomum.mec.gov.br/images/implementacao/curriculos_estados/documento_curr icular_mg.pdf $>$. Acesso em: 26/04/2021.

MINAS GERAIS. Ciclo de apresentação do currículo referência do ensino médio: conhecer para construir. Equipe de Implementação do Currículo Referência do Ensino Médio de Minas Gerais. Belo Horizonte, MG, 2020. Disponível em: < https:curriculoreferencia.educacao.mg.gov.br>. Acesso em: $30 / 03 / 2021$.

MOEHLECKE, Sabrina. O Ensino Médio e as novas diretrizes curriculares nacionais: entre recorrências e novas inquietações. Revista Brasileira de Educação, Rio de Janeiro, v. 17, n. 49, p. 39-58, jan./abr. 2012. <https://doi.org/10.1590/S1413-24782012000100003>

MOREIRA, Antônio Flávio Barbosa. Currículos e Programas no Brasil. Campinas, SP: Papirus, 1990.

MOREIRA, Antônio Flávio Barbosa. As contribuições e os impasses da teoria curricular crítica. In: CHASSOT, Attico; OLIVEIRA, Renato José de. (Org.) Ciência, ética e cultura na educação. São Leopoldo: Unisinos, 1998. p. 53-71.

MOTTA, Vânia Cardoso da; FRIGOTTO, Gaudêncio. Por que a urgência da reforma do ensino médio? Medida Provisória n. 746/2016 (Lei n. 13. 415/2017). Educação e Sociedade, Campinas, v. 38, n. 139, p. 355-372, abr./jun. 2017. <https://doi.org/10.1590/es0101-73302017176606>.

PERONI, Vera Maria Vidal; CAETANO, Maria Raquel. O público e o privado na educação: projetos em disputa? Revista Retratos da Escola, Brasília, v. 9, n. 17, p. 337-352, jul./dez. 2015.

PINTO, Samilla Nayara dos Santos. Novo Enem e Currículo do Ensino Médio: esvaziamento da formação das classes populares. Dissertação (Mestrado em Educação) 168f. Programa de Pós-Graduação em Educação, Conhecimento e Inclusão Social, Faculdade de Educação, Universidade Federal de Minas Gerais. Belo Horizonte, 2018.

SACRISTÁN, José Gimeno. O currículo: os conteúdos do ensino ou uma análise prática. In: PÉREZ GÓMEZ, A. I. Compreender e transformar o ensino. 4. ed. Porto Alegre: ArtMed, 2000. p. 16-37.

SILVA, Mônica Ribeiro da. Tecnologia, Trabalho e Formação na Reforma Curricular do Ensino Médio. Cadernos de Pesquisa, São Luís, v. 39, n. 137, p. 441-460, maio/ago. 2009. <https://doi.org/10.1590/S0100-15742009000200007>

SILVA, Mônica Ribeiro da. Currículo, Ensino Médio e BNCC - um cenário de disputas. Revista Retratos da Escola, Brasília, v. 9, n. 17, p. 367-379, jul./dez. 2015. $<$ https://doi.org/10.22420/rde.v9i17.586>

SILVA, Mônica Ribeiro da. A BNCC da Reforma do Ensino Médio: o resgate de um empoeirado discurso, Educação em Revista, Belo Horizonte, v. 34, p. 01-15, 2018. <https://doi.org/10.1590/0102-4698214130> 
SILVA, Tomas Tadeu da. Documentos de identidade: uma introdução às teorias do currículo. 3. edição. Belo Horizonte: Autêntica, 2010.

Submetido: $25 / 05 / 2021$

Aprovado: $30 / 08 / 2021$

\section{CONTRIBUIÇÃO DAS AUTORAS}

Autora 1- Coleta de dados, análise dos dados e escrita do texto.

Autora 2- Coordenadora do projeto, análise dos dados e revisão da escrita final.

\section{DECLARAÇÃO DE CONFLITO DE INTERESSE}

As autoras declaram que não há conflito de interesse com o presente artigo.

Este artigo foi publicado em preprint e está disponível em:

DOI: https://doi.org/10.1590/SciELOPreprints.2348 